\title{
Innovative technologies in mathematics teaching
}

\author{
Eshim Murotovich Mardonov ${ }^{1}$, Kurbon Ostanov ${ }^{2}$, J.Kadirov ${ }^{3}$ \\ ${ }^{1,2}$ Ph.D., Associate Professor, Samarkand State University, Uzbekistan \\ ${ }^{3}$ Samarkand State University, Uzbekistan \\ Email:m-eshim@samdu.uz ${ }^{1}$,ostonovk@mail.ru²,j.kadirov@samdu.uz ${ }^{3}$
}

\begin{abstract}
Article analyzes the fact that the answer to the question "how to teach effectively and efficiently?" Requires the development of innovative pedagogical technologies, as well as innovative technologies in teaching mathematics: technology based on problem solving, technology based on a system, effective lessons, modular technology teaching mathematics, technology master classes, technology integrated courses and provides recommendations for their implementation in practice.
\end{abstract}

Keywords: technology, pedagogical technology, innovation, lesson, modular technology, master classes, integrated courses.

\section{INTRODUCTION}

In Latin, the term "innovation" means updating, changing, attracting new things, introducing novelty. The answer to the question "how to learn effectively and efficiently?" requires the development of innovative pedagogical technologies, i.e. the model of modern educational and pedagogical activity on designing, organizing and conducting the educational process with unconditional provision of comfortable conditions for students and teachers thought out in all details [1].

The main part of the study. Among these technologies in teaching in mathematics, technology stands out on the basis of solving problems based on a personal approach, pedagogy of success, pedagogy of cooperation; teaching mathematics through problem solving; training in methods for solving standard and non-standard problems; individualization of instruction; a combination of individual and collective activities of students; a combination of lessons and extracurricular activities, non-traditional lecture lessons, practical classes (in which, analysis and discussion of the minimum number of typical tasks and exercises on the topic, each task is solved in different ways, solving an appropriate system of tasks, organizing a collective and group verification of the solution of the proposed problems, independent students compiling tasks, consulting lessons (working with cards: analysis, generalization, supplementing cards), lessons-control knowledge [2].

The second technology based on a system of effective lessons allows the creation and maintenance of a high level of cognitive interest and independent mental activity of students; appropriate use of study time; a variety of teaching methods and tools; the formation and development of ways of students' mental activity. Such lessons include the lessons of memorizing, searching for rational solutions, checking results by comparing with data, one task, creative independent work, independent work on the passed material, repetition of the passed, laboratory and practical works on geometry, binary lessons, oral control work.

The modular technology of teaching mathematics involves the study of each topic in the following sequence, an introductory lecture, a discussion in pairs and groups of replaceable composition (the training material is divided into several study modules), the exchange of teaching materials, and a control lesson.

\section{METHODOLOGY}

In technology, master classes in mathematics are not given knowledge, but are built by the student himself (in a pair or group), here the teacher only provides him with the necessary material in the form of tasks. This technology includes: individual work, work in pairs, work in groups, frontal discussion and analysis in the classroom, correction, teacher's conclusion, final stage and conclusions.

The technology of integrating mathematics allows you to build integrated courses aimed at creating a holistic and comprehensive understanding and perception of reality in students. To achieve this 
goal, it is necessary to draw up a comprehensive course program that takes into account the optimal selection of content and the principles of its design, as well as the design of integrated lessons, study assignments and ways to evaluate learning outcomes.

The problem of constructing the learning process requires the optimal solution of the following educational problems [3]: preliminary development of new material, consolidation of the passed material and verification of knowledge. In this case, the main issue is the distribution of study time. From this depends on the decision of a quality solution to a particular educational problem in the classroom.

The current classification of lessons can be reduced to two categories: special and combined lessons. At the first, the teacher focuses his activities on solving one of the above educational problems. Therefore, the lesson includes the study and repetition of the material studied, consolidation of knowledge or control and verification of knowledge and skills of students.

\section{RESULTS}

The results of the study. Innovations in teaching mathematics consist in the fact that this is a process of gradual transition of rethinking the main goals of learning in accordance with the requirements of the time. If in the past the main educational goals of learning were, now great importance is attached to the goals of developmental learning. Based on this, it is advisable that the following types of tasks in mathematics should be included in the concept of mathematics content [4]:

1. Compulsory compliance with the requirements of compulsory curricula. This means that such requirements must necessarily correspond to the knowledge, skills and competencies of each student, and at the same time, each student is expected to achieve their required level in the learning process.

2. The presence of tasks of medium difficulty.

3. Tasks that are designed for capable students with a keen interest in mathematics, as well as for use in special classes and schools, with in-depth study of mathematics and academic lyceums [5], [6], [7].

Previously, the teacher was mainly focused on the average student in his work and the implementation of the differentiated approach in mathematics was, figuratively speaking, the teacher's conscience, now innovative methods in teaching mathematics require a mandatory differentiated approach, a mandatory personality-oriented approach, According to which each student, figuratively speaking, chooses his educational trajectory. The requirements for each student and the specific work with him are determined by the level of abilities, capabilities and interests of each student.

The mathematics program of secondary schools provides for the development, first and foremost, of the intellectual sphere of students, the development of schoolchildren's thinking, the basis of which is the mental operations of analysis, synthesis, comparison, generalization, classification, the ability to draw conclusions [8], [9].

Differentiated teaching of mathematics is associated, first of all, with the improvement of setting goals for teaching mathematics. From the point of view of the technological approach, the goals of learning mathematics should be to teach students to perform some observable or presented in the form of standards of actions that form the totality of his readiness for learning, and the purpose of learning is to learn how to perform these actions. Thus, the system of goals of learning activities in this educational trajectory it can be represented as a certain system of actions of the student, adequate to the system of components of readiness for educational activity, which he must learn to complete as a result of training and for its success, and this will mean the transfer of emphasis from mathematical education to education using mathematics [10], [11], [12], [13].

\section{CONCLUSIONS}

Conclusions. At present, a teacher of mathematics has the opportunity to apply modern teaching aids. Increasingly, interactive whiteboards, multimedia projectors, and personal computers are used in the lessons.

Learning methods that promote the development and creativity of the student's personality, based on his individual characteristics, have been a priority both in traditional methods of teaching mathematics and now. This method is a personality-oriented technology. It is based on the recognition of each student's right to choose their own development path through the creation of alternative forms of learning. These 
include: training in collaboration; project method; multilevel training; Internet technologies; developmental education

The principles of instruction in collaboration of a group of students are formed by the teacher. Moreover, in each group there should be a strong student, medium and weak (if the group consists of three students); the group is given one task, but its implementation provides for the distribution of roles between group members; the work of the whole group is evaluated (i.e., the rating is put one on the whole group); the teacher himself selects the student of the group who should report for the assignment.

The method of projects involves: the presence of a significant research, creative plan problems; practical, theoretical significance of the intended results; independent (individual, paired, group) activities of students in the classroom or after school hours; structuring the content of the project (indicating phased results and the distribution of roles); use of research methods: identifying the problem, the research tasks arising from it, hypothesizing their solutions, discussing research methods, finalizing results, analyzing the data obtained, summarizing, correcting, conclusions (using the "brainstorming", "round" method in a joint study table ", creative reports, project protection, etc.). The basis of this method of projects is the development of cognitive skills of students, the ability to independently construct their knowledge, the ability to navigate the information space, analyze the information received, independently put forward hypotheses, decision-making skills, the development of critical thinking, the ability of research, creative activity.

The project method in the educational process is used to solve various small problematic tasks, and then you can organize mini-projects, training students to creatively apply their knowledge on their own. For example, the topics of such projects may be: the correct pyramid; distance from point to plane; the angle between the line and the plane; point coordinates and vector coordinates. In addition, this method is used to solve large problems that are difficult to understand. macro projects, including several lessons and a fairly serious independent search, research activity outside of class. For example, solving equations of 2 , 3, 4 degrees; function continuity; unilateral limits; remarkable limits and their evidence; Mobius strip and its properties; Golden ratio and its application in the architecture of the hometown; Pythagoras theorem and its various proofs.

\section{REFERENCES}

1. Bespalko V. P. Pedagogy and advanced learning technology /V. P. Bespalko.- M., 1995.336page.

2. Ignatov A., K. Stop the Use of innovative technologies in the educational process. Science and world International scientific journal №4(20) 2015,Vol.II, p. 69-70.

3. Abdullaev A., Ostanov K. on the implementation of information technology training in the study of the topic "Trigonometric functions". Science and the world. 2015. No. 4(20), Vol.II . R. 4142.

4. Ostanov K., Mamirov B. U., Aktamova V. U. on the METHOD OF solving PROBLEMS USING GEOMETRIC TRANSFORMATIONS / / European science. - 2019. - no. 4 (46).

5. Ostanov K., Azimov A. A., Adilova S. R. GEOMETRIC MEANING of the EQUATION WITH TWO UNKNOWNS / / Science, technology and education. - 2019. - no. 2 (55).

6. Ostanov K., Nazarov W., M. A. Barotova RANDOM variables AND THEIR DISTRIBUTION LAWS //Bulletin of science and education. - 2019. - no. 8-2 (62).

7. Ignatov A. I., Stop K. developing STUDENTS ' ABILITIES to PROVE in VARIOUS WAYS //Achievements of science and education. - 2017. - no. 6 (19) page

8. Inatov A. I., Ostanov K. METHODOLOGICAL FEATURES OF the use of methods of COMPARISON AND ANALOGY in MATHEMATICS LESSONS. Voprosy nauki I obrazovaniya. - 2017. - no. 7 (8). cyberleninka.ru

9. Ostanov, K., Inatov, A. I., Himmatov, I., \& Ruzieva, M. (2019). SOME ASPECTS OF THE STUDY OF INDETERMINATE EQUATIONS IN HIGH SCHOOL. Science and education today, (6-1 (41)).

10. Abdullaev A. N., Ignatov A. I., the Stop K. the Role and place of use of modern pedagogical technologies at the lessons of mathematics //science Symbol. - 2016. - no. 2-1.. 
11. Abdullaev A., Inatov A., Ostanov K. Some methodological features of the application of information technologies in the process of teaching mathematics / / Informatics: problems, methodology, technology. - 2016. - Pp. 7-10.

12. Ostanov K., Mardanov E. M., Ergashev A. STUDY of THEOREMS OF addition AND MULTIPLICATION of PROBABILITIES / / TOPICAL ISSUES OF MODERN SCIENTIFIC RESEARCH. - 2019. Pp. 258-261.

13. Ostanov, K., Mardanov, E. M., \& Achilov, U. (2019). METHODOLOGY OF THE STUDY OF DIOPHANTINE EQUATIONS IN EXTRA-CURRICULAR ACTIVITIES IN MATHEMATICS. BBK 72 page 114 